\title{
Canine leptospirosis in stray and sheltered dogs: a systematic review
}

\author{
Anna Cecília Costa $^{1}$, Raisa Colocho ${ }^{1}$, Carine Pereira ${ }^{1}$, Andrey Lage ${ }^{2}$, Marcos Heinemann ${ }^{3}$, \\ and Elaine Dorneles ${ }^{1}$ \\ ${ }^{1}$ Universidade Federal de Lavras \\ ${ }^{2}$ Universidade Federal de Minas Gerais \\ ${ }^{3}$ Faculdade de Medicina Veterinária e Zootecnia, Universidade de São Paulo (USP), São \\ Paulo, SP, Brasil
}

March 6, 2021

\begin{abstract}
The aim of this systematic review was to identify articles on prevalence of leptospirosis in stray and sheltered dogs worldwide and access the methodological quality of the recovered papers. Six databases (CABI, Cochrane, Pubmed, Scielo, Scopus and Web of Science) were searched, without restriction on year or location where the studies were performed. The search recovered 476 articles and 60 were selected for analysis according to quality criteria. None of the selected articles showed a complete explanation for the sample size adopted (probabilistic sampling), leading to the impossibility of recalculation of leptospirosis prevalence for stray or sheltered dogs. Among the analyzed papers $43.33 \%(26 / 60)$ showed five of the ten quality criteria analyzed, $16.67 \%$ (10/60) three, $15.00 \%$ (9/60) four, $10.00 \%(6 / 60)$ six, $6.67 \%(4 / 60)$ eight, only $5.00 \%(3 / 60)$ showed nine of the ten criteria analyzed, whereas two papers showed two $[1.67 \%(1 / 60)]$ and seven $[1.67 \%(1 / 60)]$ of the ten criteria assessed. The majority of the papers were published in the Americas [45.00\% (27/60)] and in the last sixteen years (2003 to 2019$)$ [81.67\% $(49 / 60)]$, and most of the sampled dogs were stray dogs [65.00\% (39/60)]. The leptospirosis diagnostic test used more frequently was Micro Agglutination Test (MAT) [78.33\% (47/60)] followed by polymerase Chain Reaction (PCR) [23.33\% (14/60)], whereas the most common serovars identified were Canicola [71.43\% (35/49)], Icterohaemohrragiae [65.31\% (32/49)], Grippotyphosa [40.82\% (20/49)] and Pomona [40.82\% (20/49)]. In conclusion, our results showed that Leptospira spp. is present in stray and sheltered dogs worldwide, but the complete comprehension of the prevalence of leptospirosis in these populations could not be achieved due to the low methodologic quality of the recovered studies about leptospirosis in stray and sheltered dogs.
\end{abstract}

\section{Hosted file}

Costa et al. sistematic review 02.03.2021.pdf available at https://authorea.com/users/399941/ articles/512341-canine-leptospirosis-in-stray-and-sheltered-dogs-a-systematic-review 

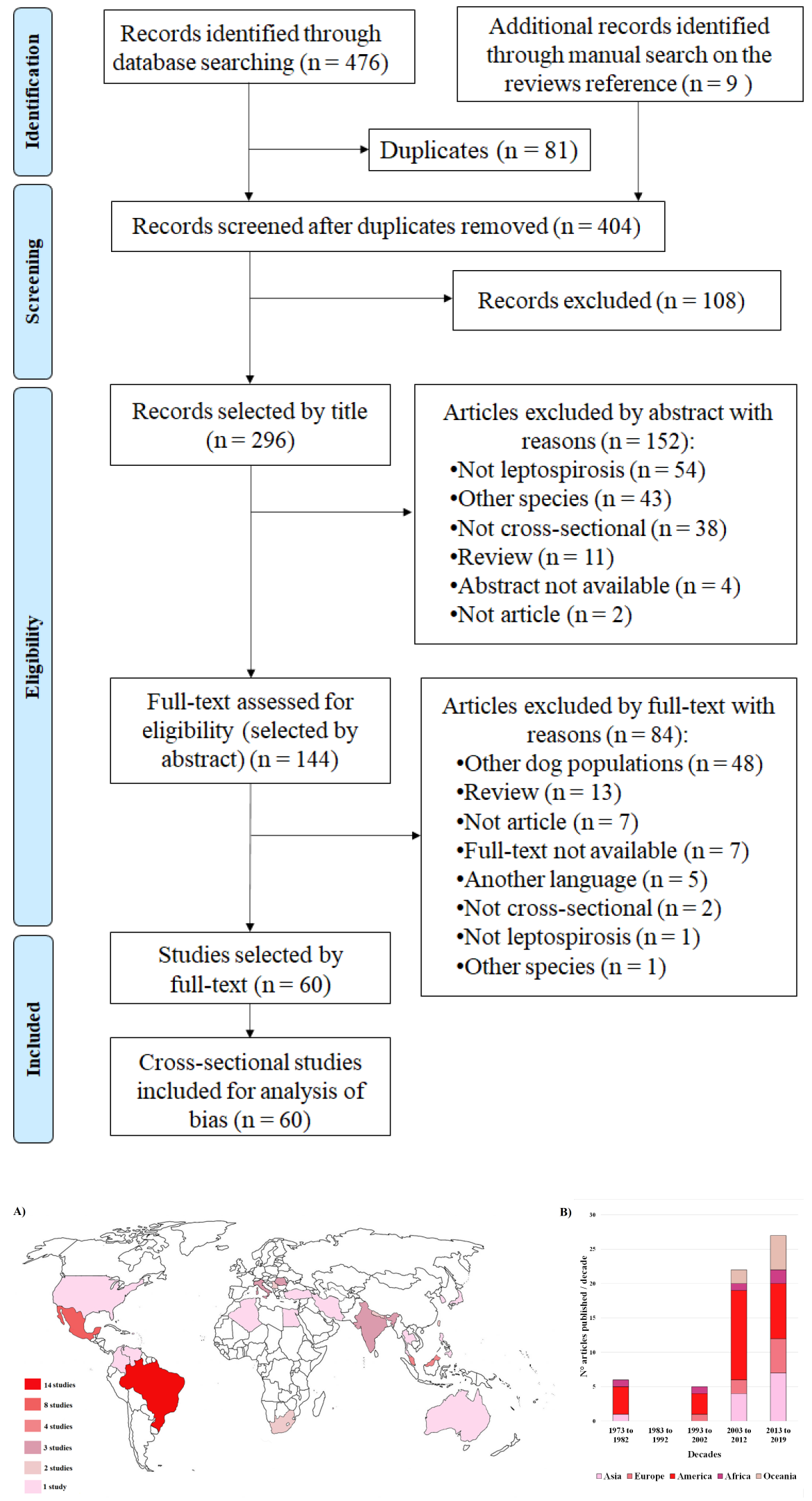


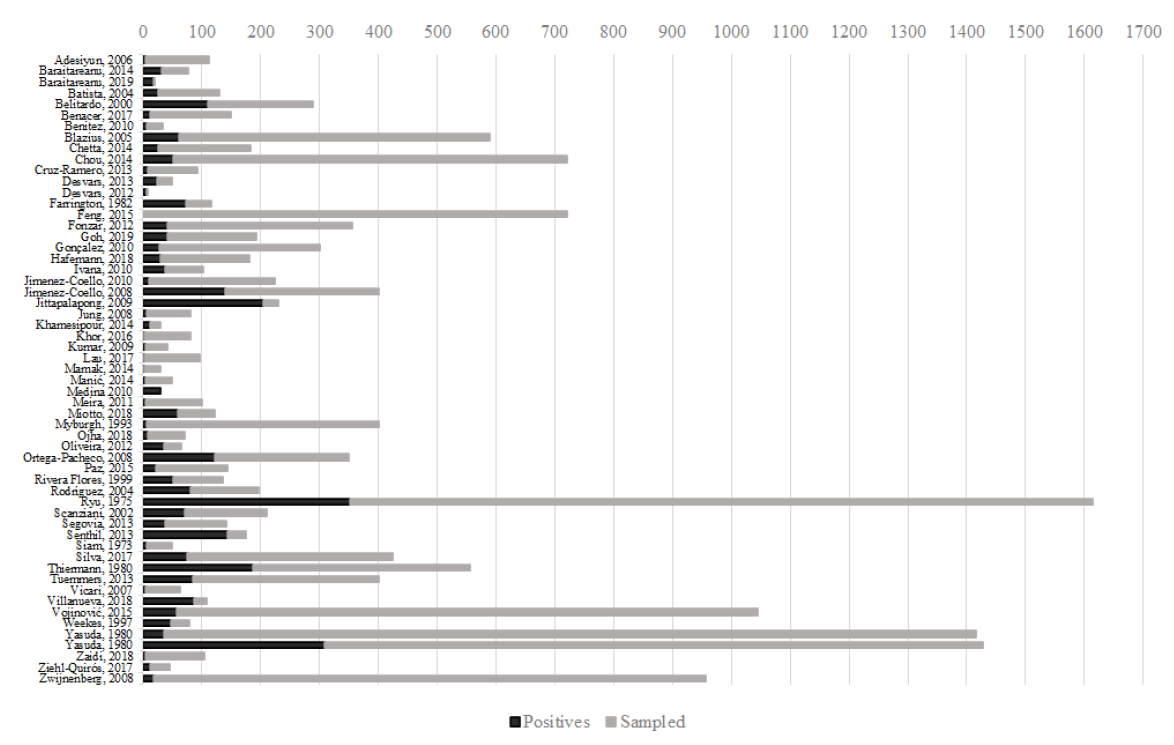


A)

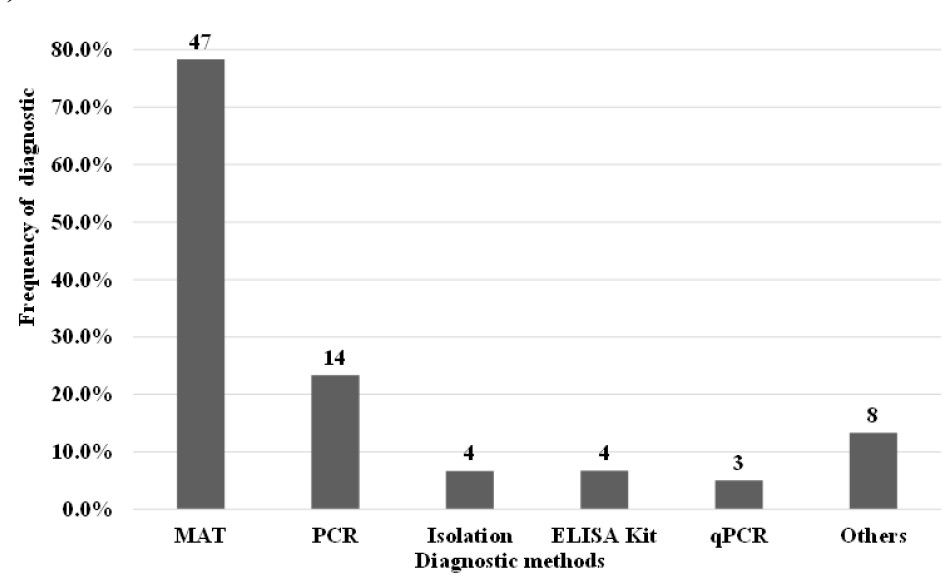

B) $\quad 80.0 \%$

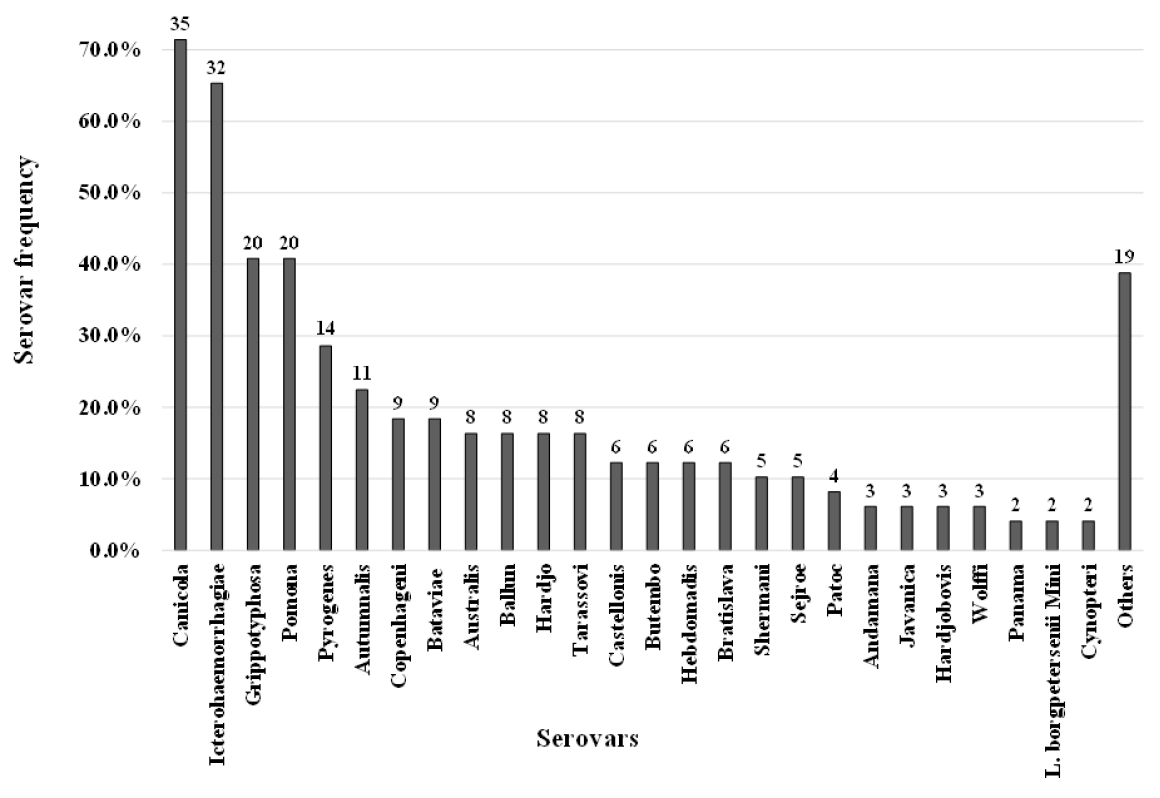

